\title{
Central retinal artery occlusion following severe blow-out fracture in young adult
}

This article was published in the following Dove Press journal:

Clinical Ophthalmology

23 April 2009

Number of times this article has been viewed

\section{Noriko Himori \\ Hiroshi Kunikata \\ Takaaki Otomo \\ Nobuo Fuse \\ Kohji Nishida}

Department of Ophthalmology and Visual Science, Tohoku University Graduate School of Medicine, Sendai, Japan
Correspondence: Hiroshi Kunikata Department of Ophthalmology and Visual Science, Tohoku University Graduate School of Medicine, I-I Seiryo-machi, Aoba-ku, Sendai 980-8574, Japan

Tel +8I $227 \mid 77294$

Fax +81227177298

Email kunikata@oph.med.tohoku.ac.jp
Abstract: A 20-year-old woman was involved in a traffic accident while riding a motorcycle. The vision in her right eye was severely reduced. At the first examination, the eyelids of her right eye were severely swollen, and the eye could barely be seen. The fundus was not visible. She had no light perception in her vision. Computed tomography revealed a severe blow-out fracture in her right eye. Surgery was immediately performed to correct the fracture and the eye globe was replaced in the orbit. On the fourth postoperative day, the right fundus was visible and a cherry-red spot and milky-white edema were seen. Fluorescein angiography showed an arterial filling defect. Four months later, her visual acuity was light perception. Our case shows that a central retinal artery occlusion can be a complication of a blow-out fracture of the lower orbital wall and can lead to severe visual loss even with early surgical repair.

Keywords: central retinal artery occlusion, blow out fracture, trauma, young adult

\section{Introduction}

Trauma to the eye and retrobulbar injections can often lead to retrobulbar hemorrhaging that can result in an increased pressure in the retrobulbar space and an occlusion of the central retinal artery (CRAO). ${ }^{1,2}$ The intraorbital pressure can be relieved by surgical drainage of the hematoma. ${ }^{1-5}$ However, a MEDLINE search did not extract any papers on cases of a blow-out fracture complicated by a CRAO, although one case of a CRAO following a blow-out fracture that was not immediately repaired has been reported. ${ }^{6}$ To the best of our knowledge, this is the first case of a blow-out fracture with a CRAO even after an early repair of the fracture.

\section{Case report}

A 20-year-old woman was involved in a traffic accident while riding her motorcycle. She most likely hit her head on the handlebar, but did not remember anything about the accident. She had a severe decrease of vision in her right eye and was referred to our Department of Ophthalmology. Her best-corrected visual acuity was no light perception (NLP) in the right eye and 1.2 in the left. Her right eyelids were severely swollen, and her right eyeball was barely visible. Movements of her right eye could not be detected because the eyeball was depressed downward. Computed tomography demonstrated that her right eye was not perforated but had shifted down into the maxillary sinus through a blow-out fracture of the lower orbital wall (Figure 1). The intraocular pressure of right eye appeared to be moderately high by palpation, and slit-lamp examination revealed corneal edema, mydriasis, and hyphema. The fundus was not visible. 


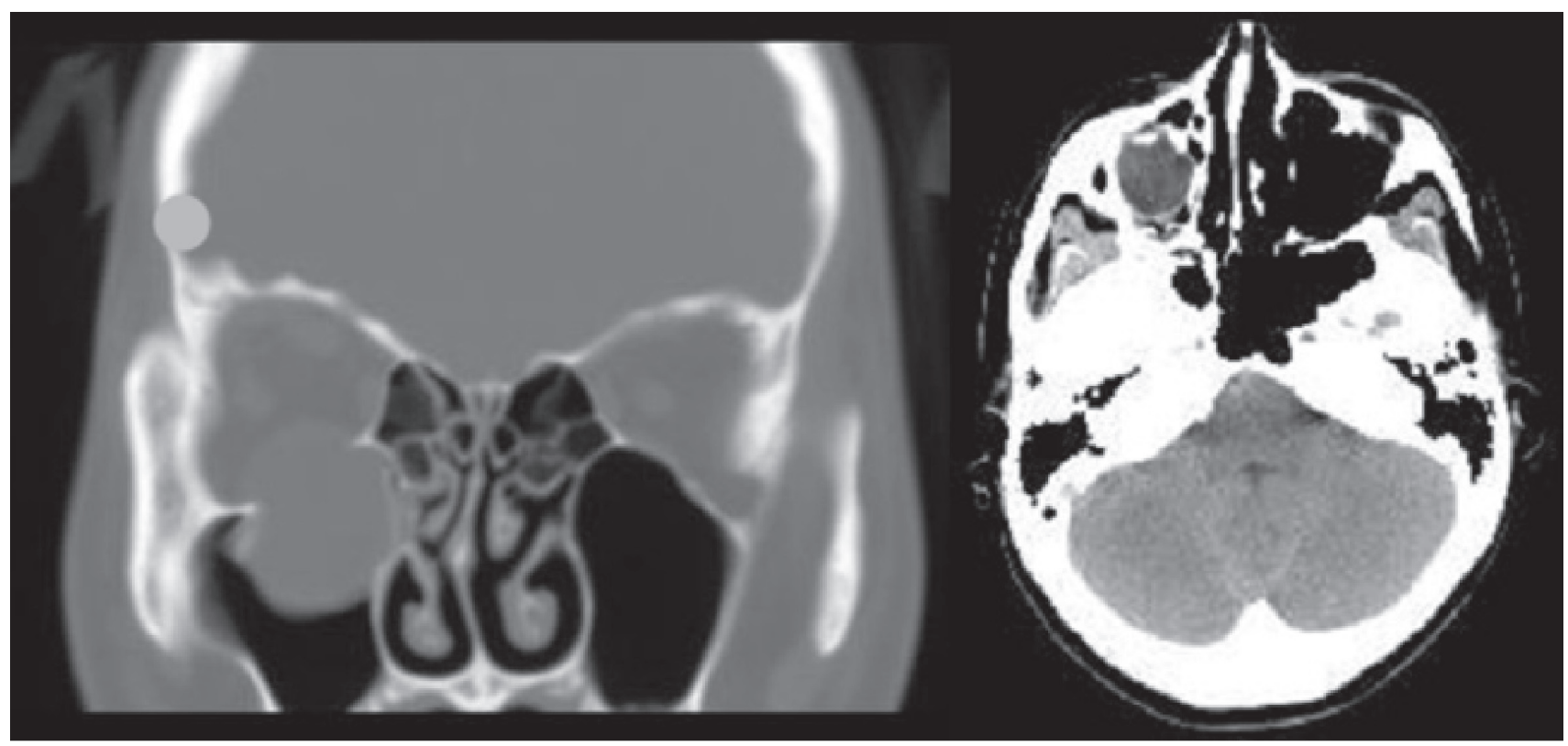

Figure I Computed tomographic images showing blow-out fracture of the lower right orbital wall. Left: Coronal section showing that the right eyeball is not perforated but has shifted downward into the maxillary sinus through the fracture of the lower orbital wall. Right: Axial section showing that her right eyeball was displaced.

Her ocular history was unremarkable, and her laboratory findings were normal. Surgery was immediately performed, and the blow-out fracture was repaired with replacement of the eyeball to its proper position (Figure 2, Left). After the surgery, her right fundus was not visible due to a hyphema, and she was treated with systemic corticosteroids for three days (methylprednisolone sodium succinate $1000 \mathrm{mg}$ /day). Her vision slowly recovered to light perception, and on the fourth postoperative day, the right fundus could be seen and showed a cherry-red spot and milky-white edema (Figure 2, Right). The edema appeared to be caused by a complete CRAO, although embolic materials were not seen. Fluorescein angiography revealed leakage on the optic disc, and a slightly delayed filling time in the right eye but an arterial filling defect was not noted. The choroidal filling was normal, and other abnormalities were not observed.

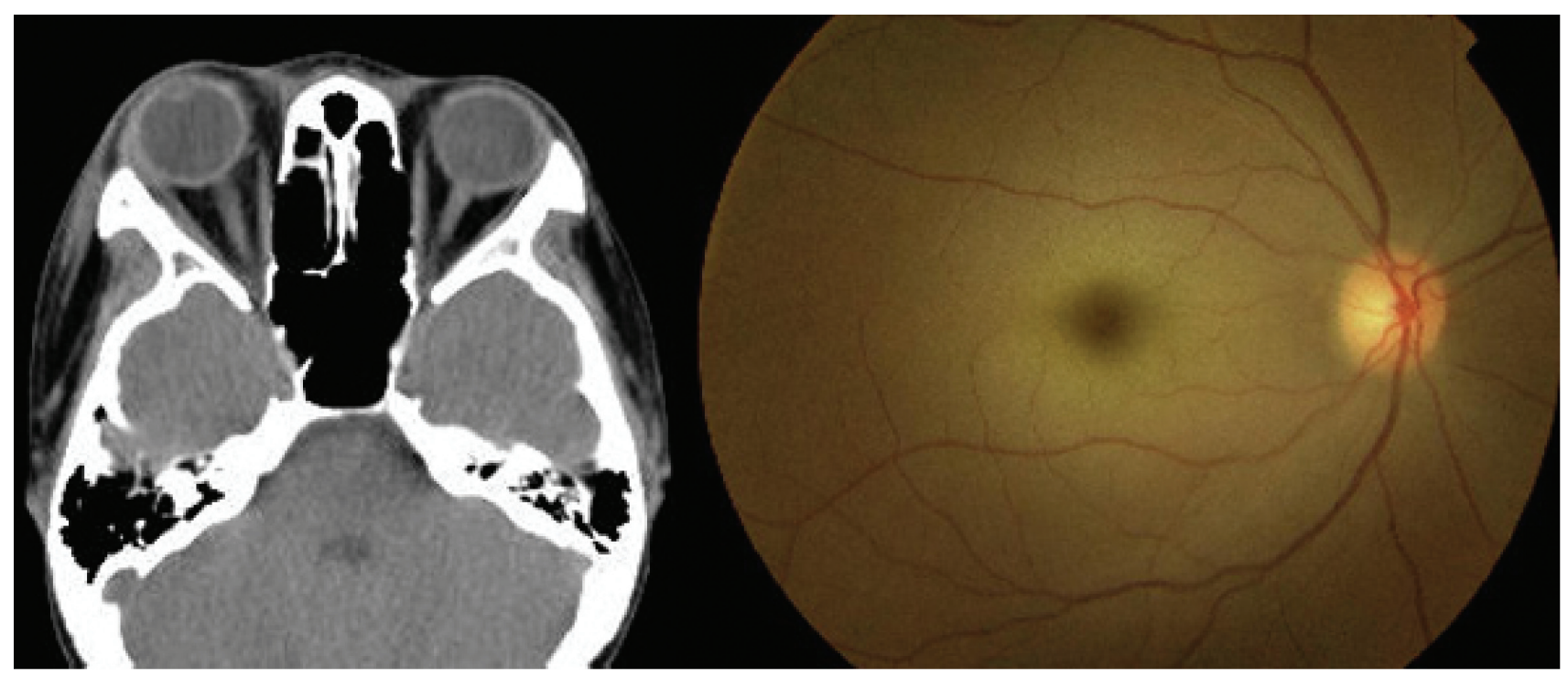

Figure 2 Postoperative computed tomographic image and fundus photograph. Left: Postoperative computed tomographic image of axial section. Blow-out fracture has been corrected and the eyeball is returned to the proper position. Right: Fundus photograph of right eye showing a cherry-red spot, milky-white lesion on macula, and mild venous dilation. 

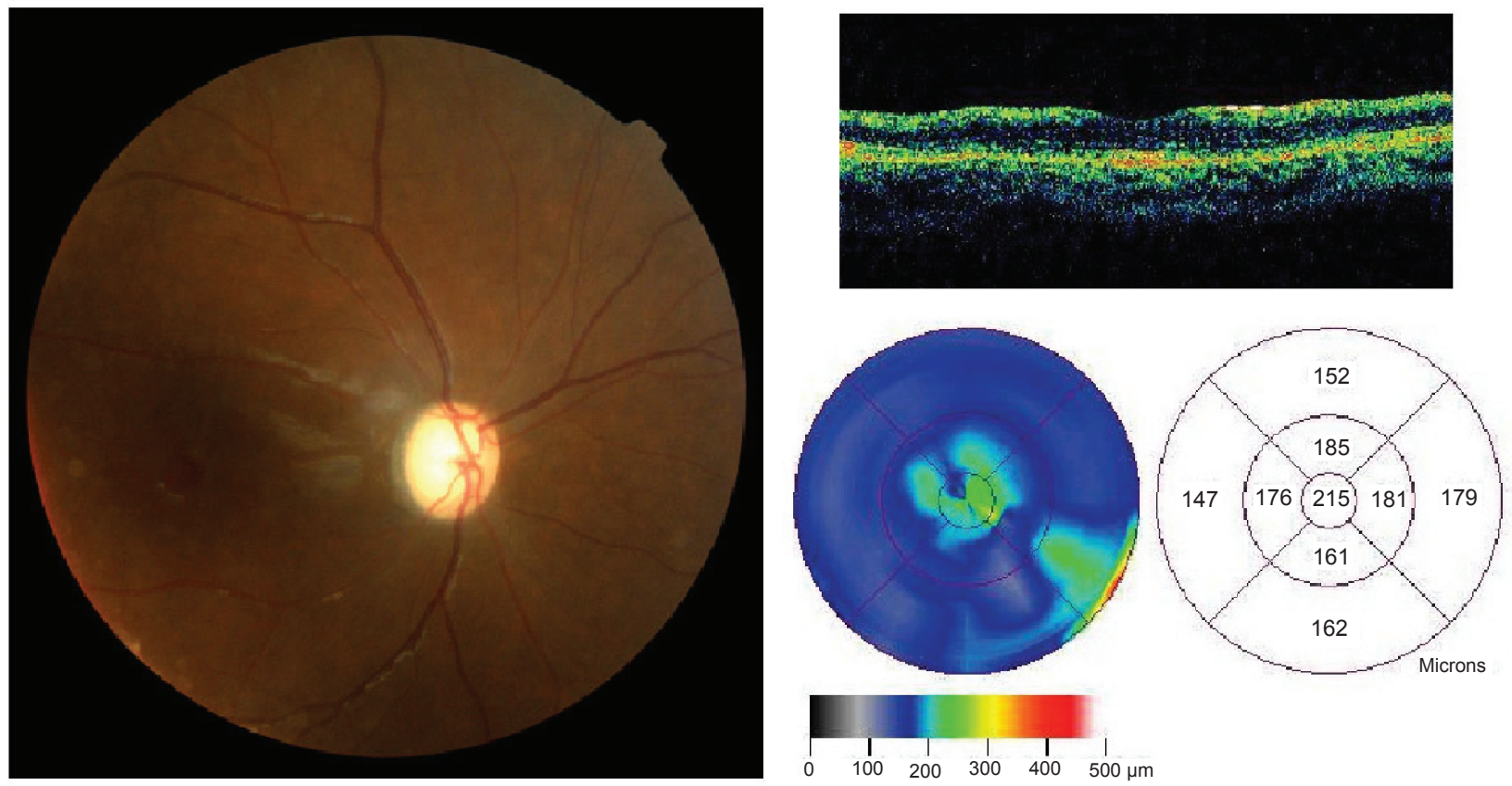

Figure 3 Optical coherence tomographic image and fundus photograph one month after the accident. Left: Fundus photograph of right eye showing optic atrophy. Right: Axial slice (upper) and retinal thickness analysis (lower) of optical coherence tomographic image.

One month later, the optic disc appeared pale and atrophic, and optical coherence tomography demonstrated that the extrafoveal region of macula was thinner than normal (Figure 3). Four months later, her visual acuity remained at light perception. Moderate dysfunction of eye movements was present in all directions.

\section{Discussion}

A blow-out fracture of the orbital wall is not uncommon, and it often leads to diplopia due to dysfunctions of the extraocular muscles. However, it is rare to have a simultaneous blow-out fracture and a CRAO. Earlier, it was reported that an 18-year-old young man was hit over the left eye with a baseball bat and his visual acuity was 1.0 in the left after the injury and before surgical intervention. ${ }^{6}$ The blow-out fracture was corrected surgically on the ninth day after injury, and several days later a CRAO developed and his vision in the end was NLP. ${ }^{6}$

Although a spontaneous CRAO is usually caused by a thorombosis or sclerotic changes, a CRAO as a complication of trauma is thought to be caused by an elevation of the intraocular pressure, mechanical stress, or injury to the optic nerve. The exact cause of the CRAO was not determined in our case, however because the blow-out fracture was very severe and eyeball was completely dislocated, an extreme stretching of the optic nerve and compression from the fractured orbital wall may have caused the transient and complete CRAO. Although the efficacy of decompression in cases of trauma is also uncertain, ${ }^{7}$ her visual outcome was poor even though surgery was performed on the day of the accident and the occlusion was considered to be relieved within several hours.

Our case demonstrates that a CRAO can be a complication of a blow-out fracture of the orbital wall and can lead to severe visual loss even with early surgical decompression.

\section{Acknowledgments}

The authors wish to thank the cooperation of Dr Takayuki Kudo, Department of Otorhinolaryngology, and Dr Yousei Ri, Department of Plastic Surgery, Tohoku University Hospital. We thank Prof. Duco Hamasaki of the Bascom Palmer Eye Institute for editing the manuscript. The authors report no conflicts of interest in this work.

\section{References}

1. Hersch M, Baer G, Dieckert JP, Lambert HM, Shore JW. Optic nerve enlargement and central retinal-artery occlusion secondary to retrobulbar anesthesia. Ann Ophthalmol. 1989;21:195-197.

2. Hodes BL, Edelman D. Central retinal artery occlusion after facial trauma. Ophthalmic Surg. 1979;10:21-23.

3. Morgan CM, Schatz H, Vine AK, et al. Ocular complications associated with retrobulbar injections. Ophthalmology. 1988;95:660-665.

4. Pierre Filho Pde T, Medina FM, Rodrigues FK, Carrera CR. Central retinal artery occlusion associated with traumatic carotid cavernous fistula: case report. Arq Bras Oftalmol. 2007;70:868-870. 
5. Chong CC, Chang AA. Traumatic optic nerve avulsion and central retinal artery occlusion following rugby injury. Clin Experiment Ophthalmol. 2006;34:88-89.

6. Emery JM, Huff JD, Justice J Jr. Central retinal artery occlusion after blow-out fracture repair. Am J Ophthalmol. 1974;78:538-540.
7. Linberg JV. Orbital compartment syndromes following trauma. $A d v$ Ophthalmic Plast Reconstr Surg. 1987;6:51-62.

\section{Publish your work in this journal}

Clinical Ophthalmology is an international, peer-reviewed journal covering all subspecialties within ophthalmology. Key topics include: Optometry; Visual science; Pharmacology and drug therapy in eye diseases; Basic Sciences; Primary and Secondary eye care; Patient Safety and Quality of Care Improvements. This journal is indexed on
PubMed Central and CAS, and is the official journal of The Society of Clinical Ophthalmology (SCO). The manuscript management system is completely online and includes a very quick and fair peer-review system, which is all easy to use. Visit http://www.dovepress.com/ testimonials.php to read real quotes from published authors. 